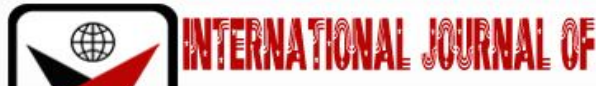

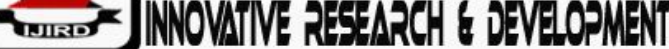

ISSN 2278 - 0211 (Online)

\section{The Evidence of Changing Rainfall Patterns in Kajiado County, Kenya}

\author{
James Kaoga \\ $\mathrm{PhD}$. Student, Institute for Climate Change and Adaptation, Nairobi, Kenya \\ George Ouma \\ Professor, Institute for Climate Change and Adaptation, Nairobi, Kenya \\ Dan Olago \\ Professor, Institute for Climate Change and Adaptation, Nairobi, Kenya \\ Gilbert Ouma \\ Senior Lecturer, Institute for Climate Change and Adaptation, Nairobi, Kenya
}

\begin{abstract}
:
The Maasai pastoralists have in the past decade experienced disruptions as precipitation season shifts. These shifts have adversely affected their economies and livelihoods. Moreover, they have been losing up to $30 \%$ of their herd annually to drought related disasters, yet the locals' capacity on climate pattern shifts is inadequate. To address this gap, a study focused on Kajiado County due to its harboring large of livestock. The study aimed at determining the historical precipitation characteristics. To achieve this, the study utilized Climate Hazards group Infra-Red Precipitation with Stations data set (CHIRPS) for the period 1983-2014 for each of the five sub-counties within Kajiado County. The key findings, encompassed: declining trend in the average annual precipitation; shifting from the usual bi-modal rainfall seasons with March to May (MAM) experiencing worst failure compared to October to December (OND) and the shortening of the famine cycles.
\end{abstract}

Keywords: Climate change, precipitation, arid and semi-arid lands, pastoral livelihood system

\section{Introduction}

The impacts of climate variability and change has been felt across the globe, however, there is a general consensus that African continent is particularly susceptible (Boko et al., 2007). In the last decade alone, the African continent has been faced with serious food insecurity attributed to successive droughts (FAO, 2010). According to Intergovernmental Panel on Climate Change (IPCC, 2013) Fifth Assessment Report (AR5) African continent has experienced a general warming trend since 1960s. The AR5 report further reiterates that majority of Africans have limited capacity to adapt to climate shifts. Though each Country is unique, such occurrences are likely to exacerbate the already existing dire conditions in the region characterized with inequitable land distribution and over-dependence on rain-fed agriculture system (Notenbaert et al., 2013; Lo' pez-Carr et al., 2014). Which have resulted into widespread poverty, food insecurity and land degradation (Notenbaert et al., 2013; Lo' pez-Carr et al., 2014). In the last decade, the Maasai pastoralists' in their large numbers have shouldered the disproportionate burden of food insecurity as a resultant in the climate shifts (Adger, 2001, 2003; Burton et al., 2006).

\section{Study Area, Data and Method of Analysis}

The precipitation characteristics were analyzed considering that soil moisture levels affect natural resources which the Maasai pastoralists in Kajiado County were highly dependent on. Indeed, precipitation affect pasture availability. Thus, the precipitation data sets were aggregated and downscaled using shape files from global Climate Hazards group Infra-Red Precipitation with Stations dataset (CHIRPS) for the period 1983-2014. This involve targeting data sets specific to Kajiado County on the basis of shape files containing ancillary data from International Livestock Research Institute (ILRI) accurately capturing the roads, rivers and administrative boundaries were an analyzed for annual and season averages using Microsoft excel. 


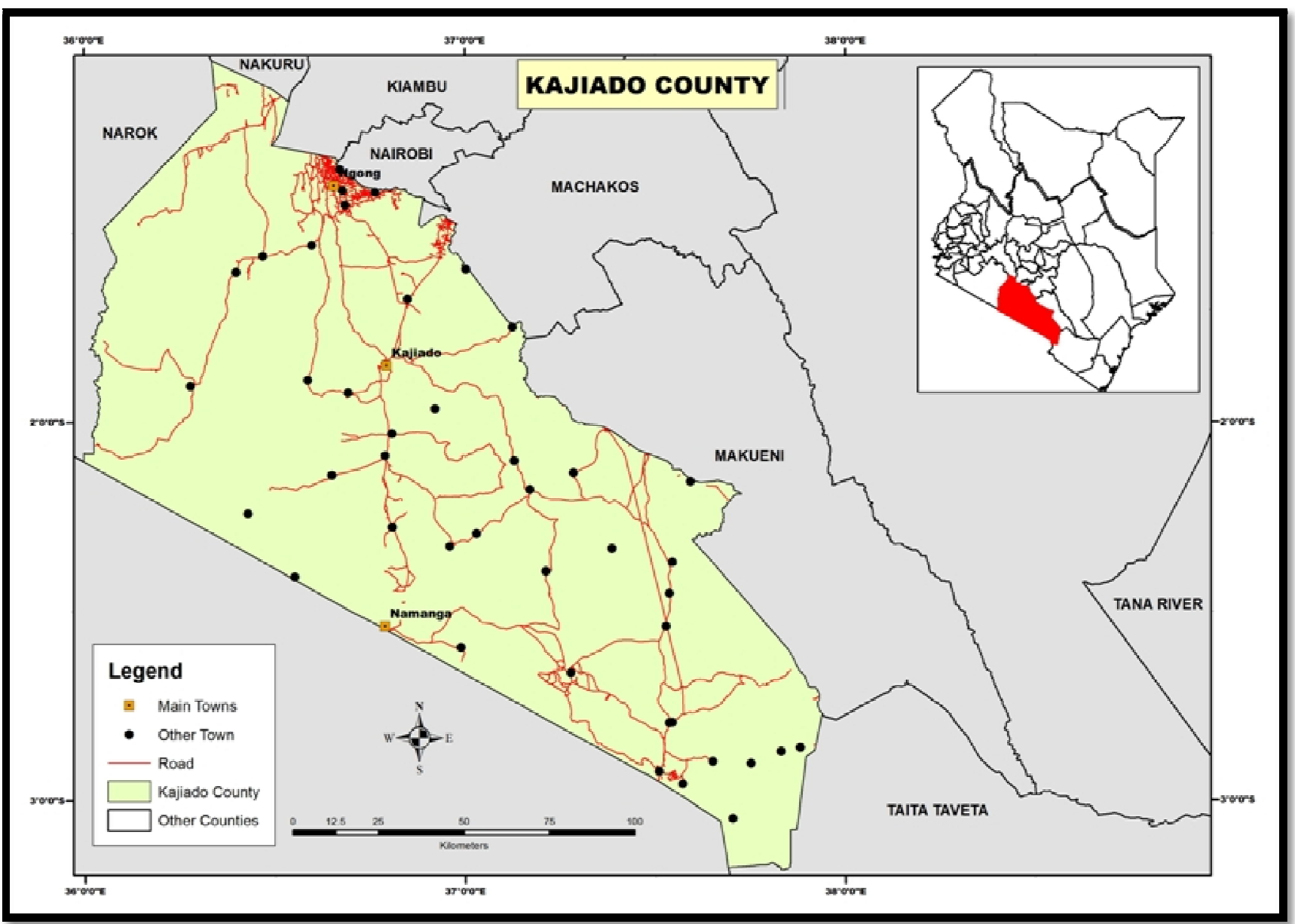

Figure 1: Study Area

Figure 1 shows that Kajiado County lies between latitude $1.85^{\circ} \mathrm{S}$ and longitude $36.78^{\circ} \mathrm{E}$ (Kajiado CIDP, 2013).

\section{Results}

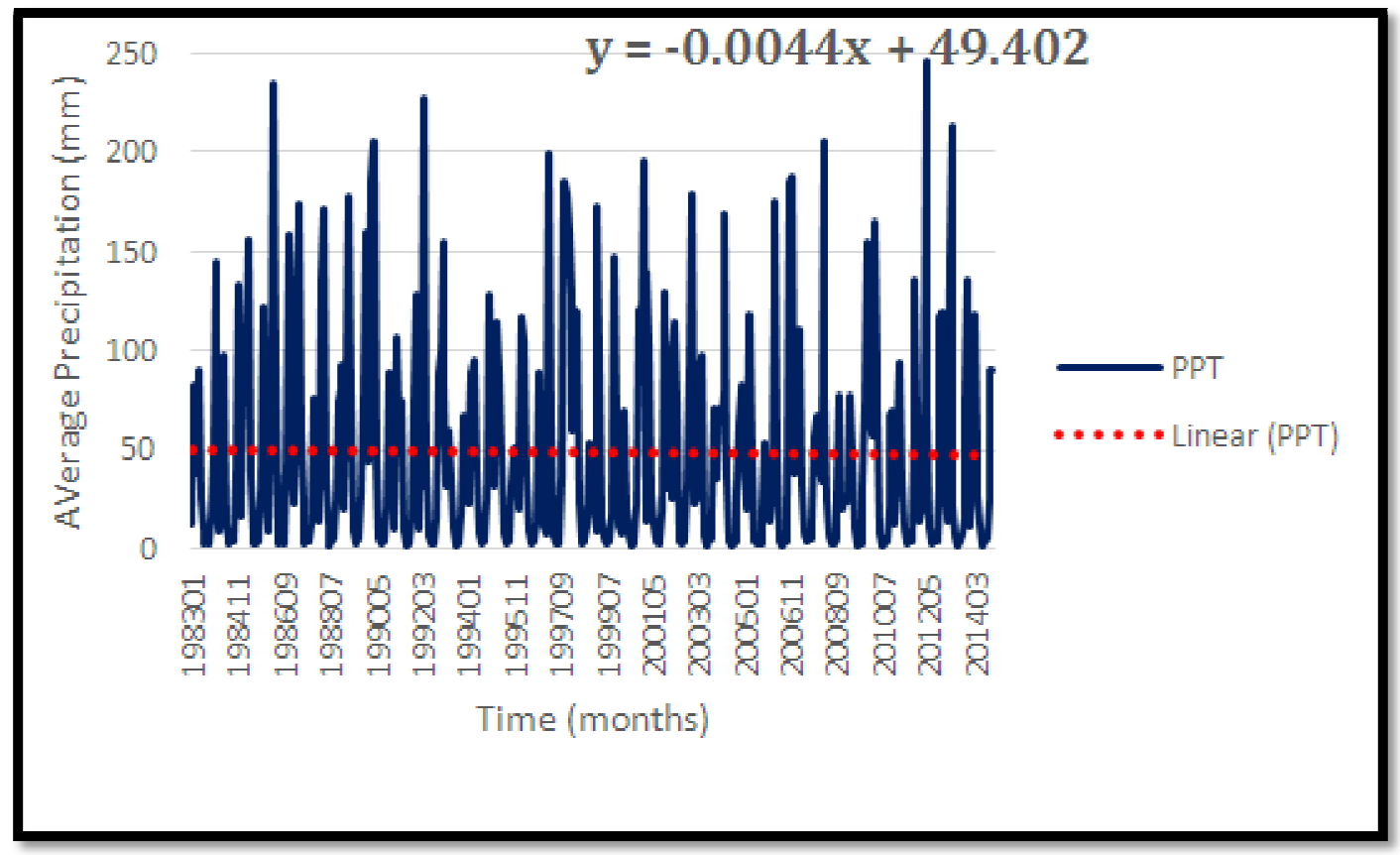

Figure 2: Average Precipitation Trend for Kajiado County (1983-2014) 
Figure 2 shows a declining precipitation trends over the 30 years study period.

Figure 3 shows spatial (the five sub-counties within Kajiado County) monthly average rainfall. The analysis indicated poor rainfall performance in the majority sub-counties, namely: Central (35-65mm), East (35-70 mm), West (30-65mm) and South $(25-70 \mathrm{~mm})$ with exception of the North $(40-105 \mathrm{~mm})$ having recorded enhanced monthly average range of precipitation.
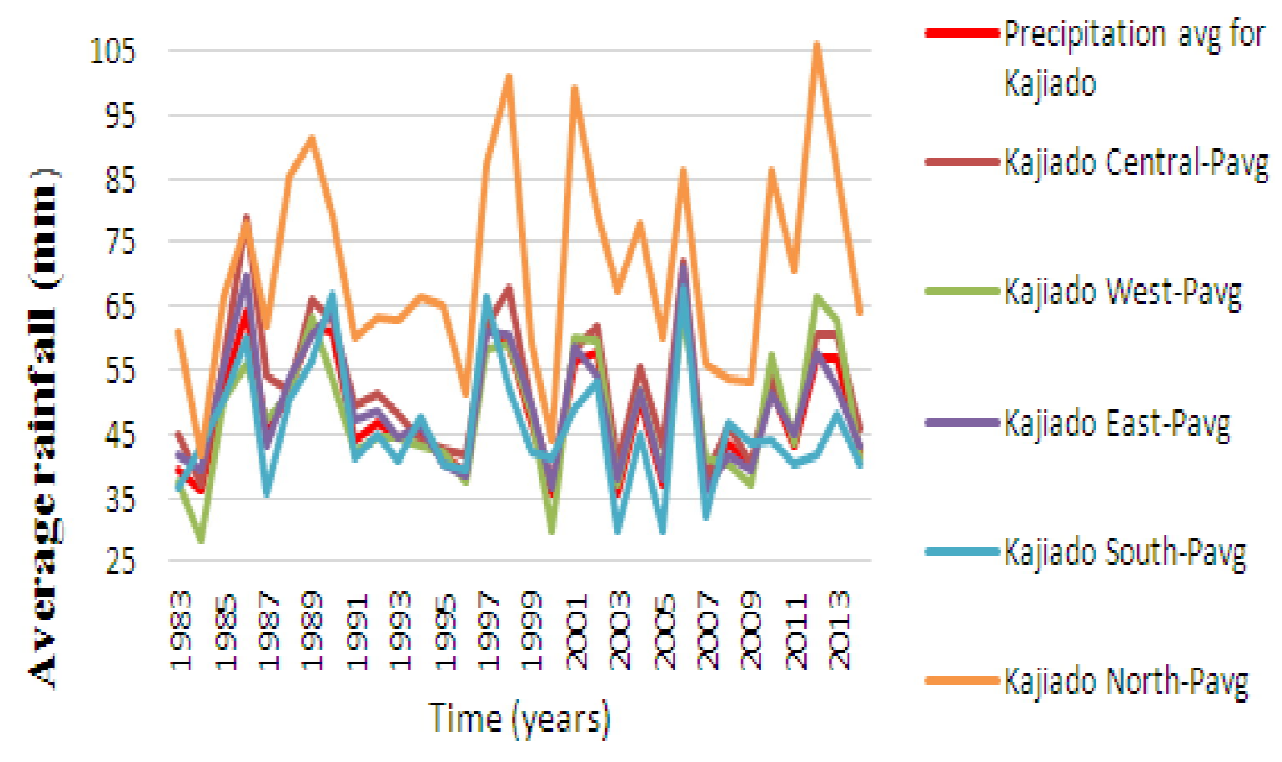

Kajiado West-Pavg

Kajiado East-Pavg

Cajiado South-Pavg

Cajiado North-Pavg

Figure 3: Kajiado Sub-County Average Rainfall (1983-2014)

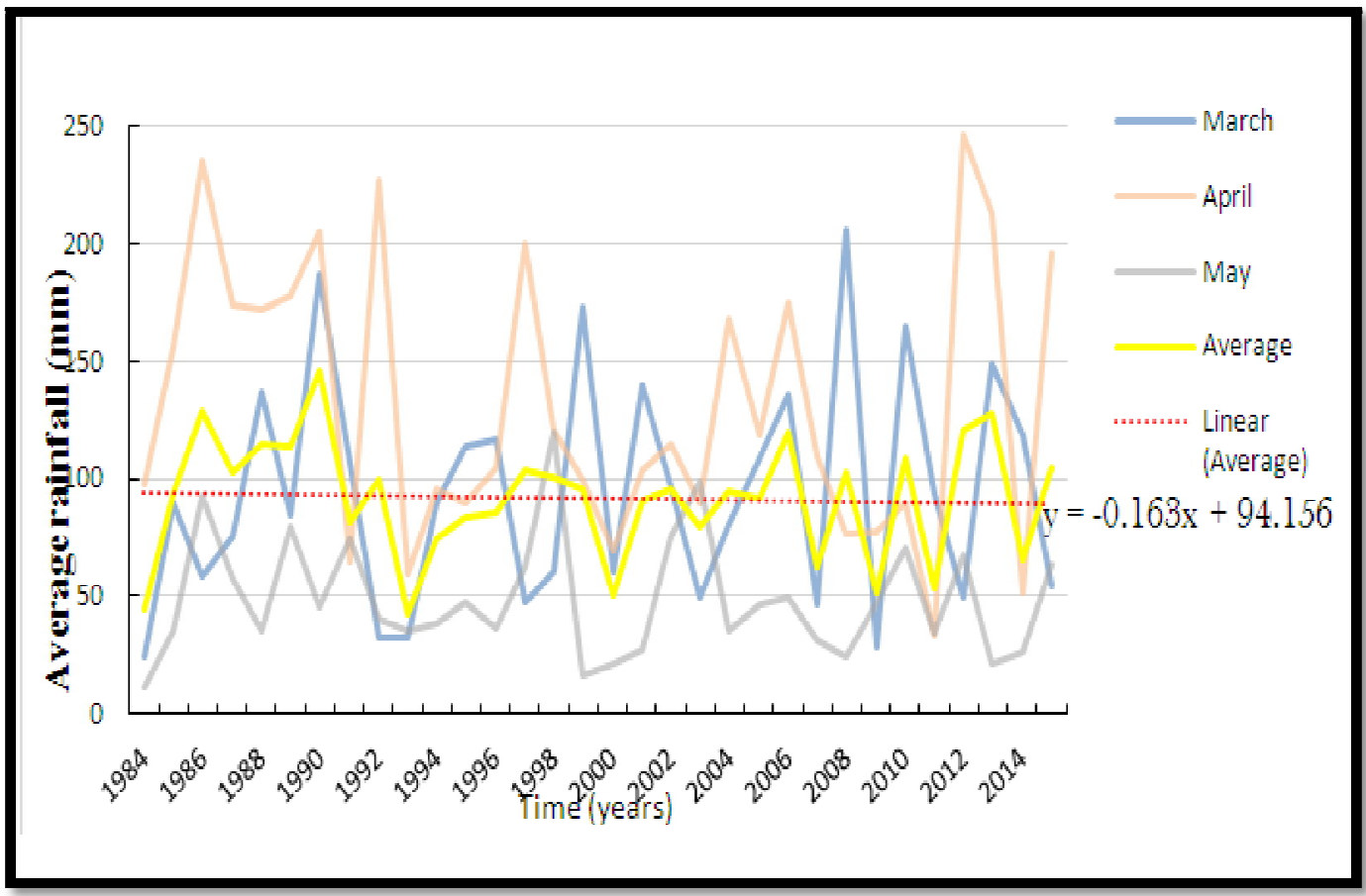

Figure 4: Time Series for Main Rainy Season (MAM) for Kajiado County

Figure 4 shows time series for main rainy season March to May (MAM) averages for Kajiado County over the past 30 years. The study showed declining MAM's average over the past 30 years. The regression analysis shown that the monthly mean rainfall for the County was decreasing at $0.163 \mathrm{~mm}$ monthly $(\mathrm{y}=0.163 \mathrm{x}+94.156)$. Moreover, 2004, 2007, 2009, 2011, and 2014 recorded low precipitation significantly shortening the famine cycles. 


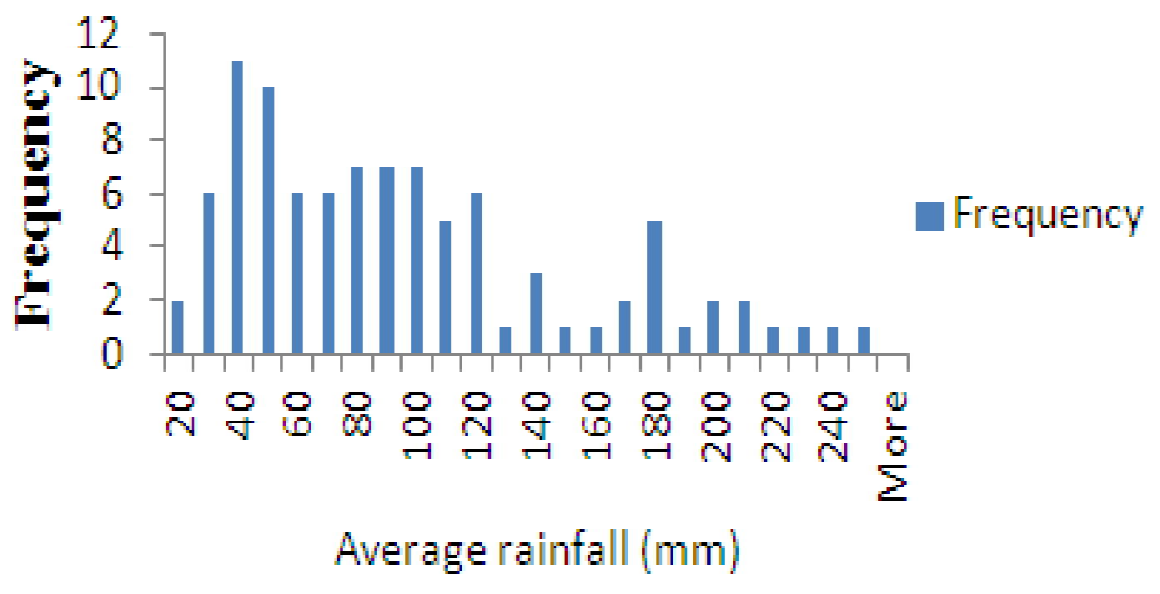

Figure 5: Histogram for MAM in Kajiado County

Figure 5 shows the cumulative amount of rainfall received during 30 years period (1984-2014). The histogram illustrates the MAM's rain episodes Kajiado County over the same period. On a closer look, more episodes of precipitation were inclined towards the left (low rainfall). This simply imply that most of the rainfall episodes were generally poor with a modal frequency of $40 \mathrm{~mm}$ as the average recorded over the three months i.e. March to May.

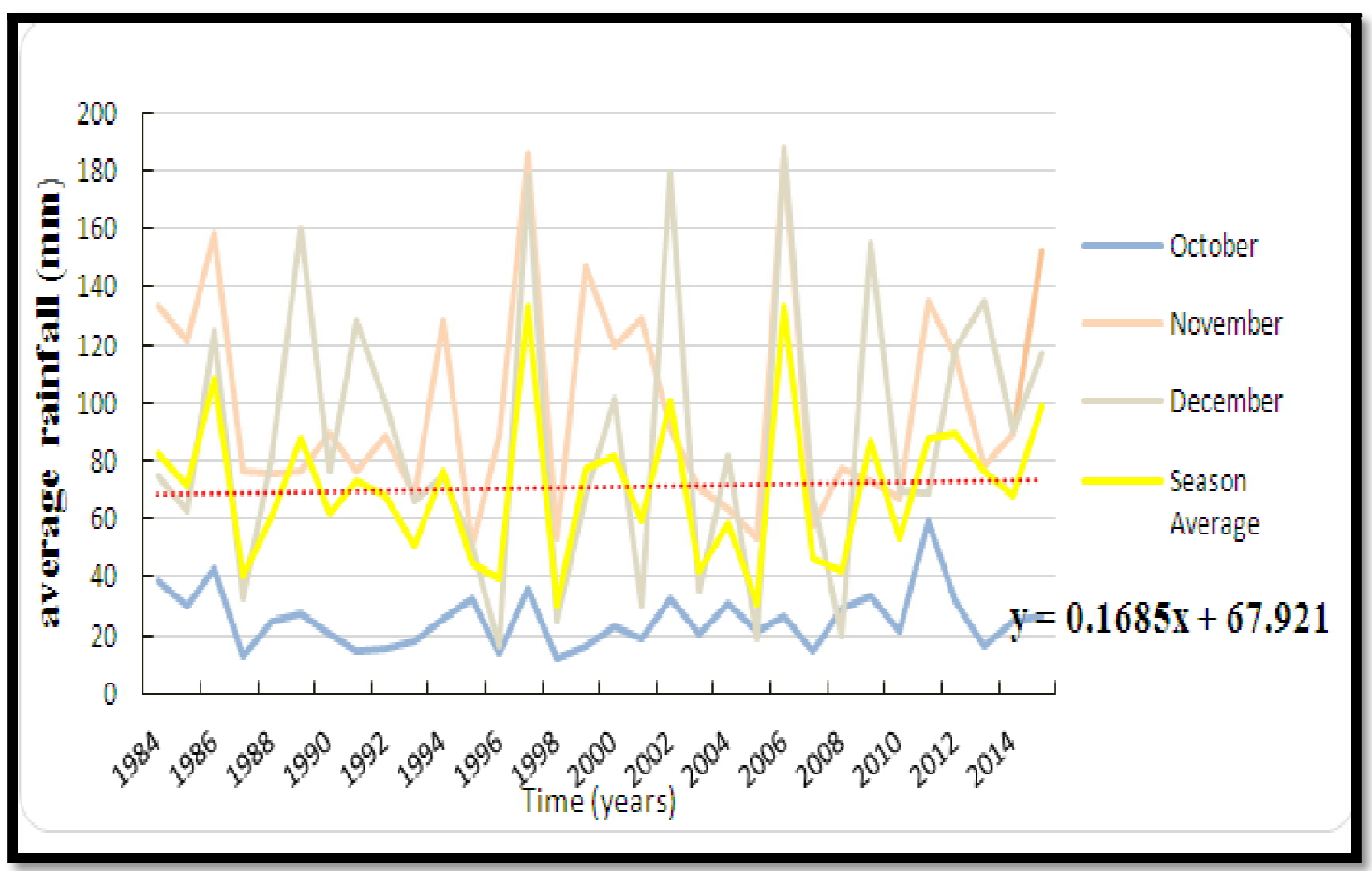

Figure 6: Variation of OND Rainfall in Kajiado County

Figure 6 shows the OND seasonal monthly averages for Kajiado County. The analysis showed positive (ascending) trend line indicating an increase in precipitation received during the OND season contrary to MAM's. 


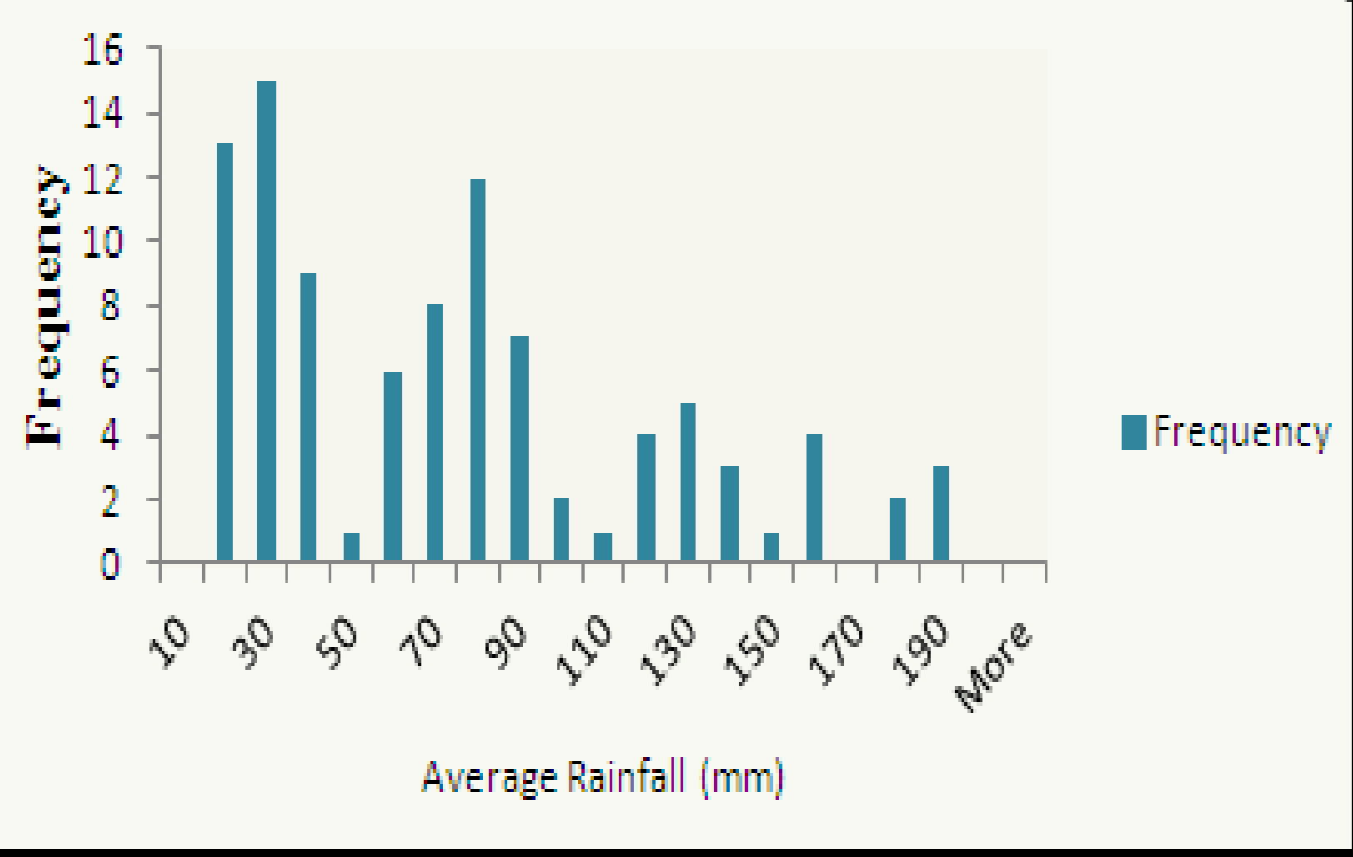

Figure 7: OND Histogram for Kajiado County

Figure 7 shows the average cumulatively rainfall recorded with most of the rainfall episodes inclined towards the left (low rains). This simply imply that most of the rainfall episodes were generally poor with October to December average a modal frequency of $30 \mathrm{~mm}$.

\section{Discussion}

Precipitation characteristics were analysed over the past 30 years period. The study showed a declining trends in the annual average rainfall (figure 1). Meanwhile, the spatial aspect (sub-counties) focused on monthly averages (figure 2), namely: Central (35-65mm), East (35-70mm), West (30-65mm) and South $(25-70 \mathrm{~mm})$ which were low with an exception of the North having recorded enhanced precipitation $(40-105 \mathrm{~mm})$. This spatial variability was partially attributed to North's agro-climatic zones. This is in agreement with Ogallo (1993), who noted that highly elevated areas receive enhanced rainfall compared to the low-lying areas. However, generally, the County was becoming drier (NEMA,2005:4.) wih a monthly average of $45 \mathrm{~mm}$.

Indeed, seasonal variations was evident. For instance, the main rainy season March to May (MAM) had recorded less precipitation compared to October to December (OND). This is in agreement with Amwata, 2013 who's stated that the County receives a bi-modal rainfall pattern however they are less predictable. In terms of cumulative rainfall averages, the histograms (figures 5 and 7) affirmed low episodes of rains during the MAM season with occasional enhanced rains over OND. This was despite, their high dependence on the two rainy seasons (Butt et al., 2009; GOK, 2007b). Meaning that these successive rain failures limits challenges their ability to secure their livelihood. Despite these limitations, livestock production still accounted for most of their income (Kirimi et al., 2013). Thus, the need for diversification to reduce their dependency on rainy seasons which are unpredictable.

\section{Conclusion}

Generally, Kajiado County recorded low rains in most of its sub-counties (Central, East, West and South) with an exception of the North. This could have been attributed to the difference in the Agro-ecological zones whereas the North being highly elevated in its altitude thus it could receive comparatively high level of precipitation (Ogallo, 1993). Meanwhile, March to May (MAM) the main rainy season and October to December (OND) short rainy seasons characterised by oscillatory patterns with many instances of low (depressed) rains alternating with occasional high rains as illustrated in the histograms (figures 5 and 7). For instance, 1998 El-Nino (heavy downpour which were accompanied by floods, soil erosion and land degradation). Meanwhile, the main rainy season which ought to have contributed much to the total annual average rainfall were low across the study period reflecting in the decline of the annual average rainfall (figure 1). These were reflected across the study period; however, they were more pronounced in 2014, 2011, 2009, 2007 and 2004.

\section{Recommendation}

The changing precipitation patterns calls for the Maasai pastoralists to be more prepared. More so, change of perceptions. Indeed, this requires platform which will involve and empower the locals in the interpretation of key weather attributes through mass broadcast coverage in local dialect be sustained for some time since their livelihood is under threat. 
Thus, calling for sensitization and additional support to boast complementary income generating activities alongside the traditional practices in Kajiado County, Kenya.

\section{Acknowledgement}

I am grateful to the Regional Centre for Mapping of Resource for Development (RCMRD) and IGAD Climate Prediction and Application Centre (ICPAC) for allowing me access to Geospatial and Geo CLIM software, respectively. Finally, this research could not have been implemented without financial support from the National Council of Science and Technology (NACOSTI) and I would wish to express my sincere gratitude to them.

\section{Reference}

i. Amwata, D.A.2013. Influence of climate variability and change on livelihoods in Kenya southern rangelands. PhD thesis submitted to the department of Rangeland Resource Management and Agricultural Technology, UON

ii. Birch,I. and Grahn, R. (2007), "Pastoralism-Managing Multiple Stressor and the Threat the Threat of climate Variability and Change" , Human Development Report Office Occasional Paper 2007/ 45,UNDP

iii. Boko, M., Niang, L., \& Nyong, A. (2007). Impacts, adaptaion and vulnerability. In Africa Climate Change (pp. 433-467). UK: Cambridge University Press.

iv. FAO (Ed.). (2010). Weather and Agriculture in Kenya (1st Edition ed.). Nairobi: Government printers.

v. Government of Kenya. (2007b) National Policy for Sustainable Development of ASALs

vi. IPCC. (2013). Summary for Policymaers. In : climate Change 2013: The physical Science Basis. Contribution of Working Group 1 to the Firth Assessment Report of the Intergovermental Panel on Climate Change. (T. Stocker, D. Qin, G. K. Plattner, M. Tignor, S. K. Allen, J. Boschung, et al., Eds.) Cambridge, U.K.: Cambridge University Press.

vii. Kajiado County Integrated Development Plan. (2013). Kajiado: County Government of Kajiado

viii. Ogallo, L.A. (1993) Dynamism of Climate Change over Eastern Africa. Proc. Indian Academy of Science 102, 1,203217 